\title{
Imunoensaios: uma alternativa para a detecção de fungos toxigênicos em alimentos
}

\section{Immunoassays: an alternative for toxigenic fungi detection in foods}

\author{
Paula Garcia Meirelles ${ }^{1}$; Luciana Biazon ${ }^{1}$; Mario Augusto Ono²; \\ Elisa Yoko Hirooka ${ }^{3}$; Elisabete Yurie Sataque Ono ${ }^{4 *}$
}

Resumo

O monitoramento constante da contaminação fúngica é imprescindível para assegurar a qualidade e segurança dos alimentos, reduzindo as perdas econômicas, assim como os riscos à saúde humana e animal. Os métodos tradicionais de identificação e detecção de fungos (cultivo em diversos meios, exame microscópico e análises bioquímicas) geralmente consomem muito tempo e exigem pessoal com experiência. Os imunoensaios, particularmente os ensaios imunoenzimáticos, constituem uma alternativa promissora aos métodos tradicionais devido à alta sensibilidade, especificidade, reprodutibilidade e potencial como método rápido de controle de qualidade. Dentre os ensaios imunoenzimáticos, aqueles baseados em exoantígenos são os mais empregados na resolução de problemas taxonômicos, detecção e identificação de fungos toxigênicos. Nesta revisão serão abordados conceitos básicos de imunoensaios, métodos de detecção de fungos, assim como diversos ensaios imunoenzimáticos para a detecção de fungos toxigênicos em alimentos.

Palavras-chave: Imunoensaios, fungos toxigênicos, detecção de fungos, imunodetecção

\begin{abstract}
Constant monitoring of mould contamination is essential in order to assure the food quality and safety and reduce the economic losses, as well as to minimize the potential hazards to human and animal health. The traditional methods for mould identification and detection (culture in several media, microscopic examination and chemical analysis) are usually time-consuming and require trained staff. Immunoassays, particularly enzyme-linked immunosorbent assay (ELISA) could be a promising alternative to the traditional methods due to high sensitivity, specificity, reproducibility and potential for use in rapid quality control. Among ELISAs, those based on exoantigens are the most employed in the resolution of taxonomic problems, detection and identification of toxigenic fungi. This review discusses the basic principles of immunoassays, methods of mould detection and the several ELISAs developed for toxigenic fungi detection in food.
\end{abstract}

Key-words: Immunoassays, toxigenic fungi, mould detection, immunodetection

1 Bacharel em Ciências Biológicas pela Universidade Estadual de Londrina, Mestre em Biotecnologia pela Universidade Estadual de Londrina.

2 Docente do Programa de Pós-Graduação em Patologia Experimental - Departamento de Ciências Patológicas / CCB/UEL.

3 Docente do Programa de Pós-Graduação em Ciência de Alimentos - Departamento de Tecnologia de Alimentos e Medicamentos/ CCA/ UEL.

${ }^{4}$ Docente do Programa de Pós-Graduação em Biotecnologia do Departamento de Bioquímica e Biotecnologia/CCE/UEL, Campus Universitário. E-mail: eysono@uel.br.

* Autor para correspondência 


\section{Introdução}

Os fungos estão amplamente distribuídos na natureza e são contaminantes comuns de alimentos, grãos e rações, que por apresentarem nutrientes como carboidratos, proteínas e lipídeos constituem um substrato adequado para o desenvolvimento de microrganismos (GOURAMA; BULLERMAN, 1995). Determinados fungos contaminantes de produtos agrícolas produzem metabólitos secundários tóxicos denominados micotoxinas, que podem provocar intoxicações em seres humanos e animais (BENNET; RICHARD, 1994). Desta maneira, a caracterização e identificação de fungos contaminantes de alimentos são essenciais para o controle da contaminação por estes microrganismos e a possível produção de micotoxinas.

Dentre os principais fungos toxigênicos em alimentos destacam-se os gêneros Aspergillus, Fusarium, Penicillium, Alternaria e Myrothecium, capazes de produzir micotoxinas em grãos no campo, durante a colheita, transporte e armazenagem (AYRES, 1979; LI; MARQUARDT; ABRAMSON, 2000).

Os métodos tradicionais de identificação e detecção de fungos incluem o cultivo em diversos meios, exame microscópico e análises bioquímicas (quitina, ergosterol e metabólitos secundários) (JARVIS et al., 1983). A maioria destes métodos apresenta baixa especificidade e reprodutibilidade, além de consumirem tempo e exigirem pessoal técnico qualificado para a execução (LI; MARQUARDT; ABRAMSON, 2000). Recentemente, estudos de sistemática molecular têm sido realizados na tentativa de facilitar a diferenciação de espécies fúngicas, mas embora possuam boa especificidade, essas metodologias apresentam custo elevado e exigem pessoal técnico qualificado (KERÉNYI et al., 1999; STEENKAMP et al., 2000).

Por outro lado, os métodos imunológicos apresentam várias vantagens, como rapidez na obtenção de resultados, alta sensibilidade e facilidade na execução. Dentre os ensaios imunoenzimáticos
(ELISA - "enzyme-linked immunosorbent assay"), os que utilizam exoantígenos são os mais empregados na resolução de problemas taxonômicos, deteç̧ão e identificação de fungos toxigênicos (LU et al., 1994; ABRAMSON et al., 1998; THORNTON et al., 2002).

Neste artigo serão abordados conceitos básicos de imunoensaios, métodos de detecção de fungos, assim como diversos ensaios imunoenzimáticos para a detecção de fungos toxigênicos em alimentos.

\section{Conceitos Básicos de Imunoensaios}

Os antígenos de fungos podem ser preparados a partir de células totais, ou partes das células, esporos, produtos metabólicos, ou sobrenadante de cultura de fungos (COUSIN et al., 1990) A maioria dos antígenos de fungos tem sido obtida de componentes solúveis das células, ou do meio no qual eles se desenvolveram.

Exoantígenos são moléculas imunogênicas solúveis, secretadas por fungos no meio de cultura. Muitos fungos produzem antígenos que são específicos para um gênero e/ou espécie, portanto podem ser utilizados para identificação, apresentando grande aplicabilidade na imunoidentificação de fungos patogênicos e na resolução de problemas taxonômicos (KAUFMANN; STANDARD, 1987).

Existem vários métodos que podem ser empregados na obtenção e purificação de exoantígenos. O meio utilizado, a temperatura, o tempo de incubação e a condição de cultivo (estática ou agitada) variam conforme o fungo considerado. A principal preocupação consiste em produzir uma cultura com ampla variedade de antígenos. Para a produção de exoantígenos ou antígenos miceliais é necessário utilizar um meio que seja desprovido de antígenos que possam apresentar reação cruzada no ensaio. Após o crescimento do fungo em um período determinado e temperatura apropriada, o meio pode ser decantado e recuperado após centrifugação ou filtração. O filtrado resultante pode ser 
adicionalmente purificado e concentrado por membrana, ou por ultrafiltração seguida de diálise. Os antígenos também podem ser purificados por precipitação, cromatografia de afinidade ou métodos similares. Para produzir antígenos de esporos ou de micélio, as células fúngicas devem ser lavadas, centrifugadas e secas e em alguns casos devem ser tratadas quimicamente ou aquecidas para inativação (NOTERMANS et al., 1998).

Os animais possuem a capacidade de produzir anticorpos, glicoproteínas séricas, quando estimulados por uma substância estranha denominada antígeno. Os anticorpos ligam-se com alta especificidade aos epítopos dos antígenos por meio dos sítios combinatórios (ROITT; BROSTOFF; MALE, 2003). Calcula-se que um animal possa produzir 1 bilhão de diferentes anticorpos, capazes de interagir com diferentes epítopos (ABBAS; LICHTMAN; POBER, 2000). Quando um antígeno penetra no organismo de um animal, ocorre ativação dos linfócitos B que apresentam na superfície um receptor adaptado ao seu reconhecimento e fixação (ROITT; BROSTOFF; MALE, 2003).

A especificidade das reações antígeno-anticorpo faz dos métodos imunológicos ferramentas eficientes no diagnóstico de doenças causadas por fungos, protozoários, bactérias e vírus (MARINHO, 2001).

Os imunoensaios são procedimentos analíticos baseados na ligação não covalente entre antígeno e anticorpo, e podem ser utilizados para detecção do antígeno ou do anticorpo. $\mathrm{Na}$ área de alimentos, os imunoensaios utilizados são baseados na pesquisa de antígenos e podem empregar anticorpos policlonais, monoclonais ou anticorpos recombinantes (HEFLE, 1995).

Os anticorpos policlonais consistem de uma mistura de moléculas de anticorpos produzidos por diversos clones de linfócitos B. A obtenção de anticorpos policlonais é geralmente simples, de baixo custo e requer menos tempo do que para a produção dos monoclonais. $\mathrm{O}$ animal (geralmente camundongo ou coelho) é imunizado com várias doses do antígeno e o anticorpo é purificado do soro. O estágio de purificação pode envolver a remoção de anticorpos não específicos através de processos de adsorção. Devido à presença de anticorpos com diferentes especificidades, a ocorrência de reação cruzada pode gerar resultados falso-positivos, além disso, há variabilidade na resposta de cada animal. Os anticorpos monoclonais, por outro lado, correspondem a moléculas de imunoglobulinas secretadas de células híbridas resultantes da fusão de células de mieloma com clones de linfócito B. Cada clone representa uma fonte potencial de grandes quantidades de um único tipo de anticorpo altamente específico direcionado a apenas um epítopo. A obtenção de um anticorpo monoclonal requer um período de 6 a 18 meses (CANDLISH, 1991).

Recentemente, foi introduzida uma nova metodologia para produção de anticorpos baseada em anticorpos recombinantes, que consistem de fragmentos de anticorpos expressos em bactérias, fagos ou fungos. Esta técnica possui como vantagens o baixo custo e a possibilidade de manipulação genética para aumentar a especificidade e afinidade do anticorpo (YAU; LEE; HALI, 2003).

\section{Métodos Para Detecção de Fungos}

Os métodos tradicionais de identificação e detecção de fungos incluem cultivo em vários meios, análise microscópica e métodos químicos (análise de quitina, ergosterol ou metabólitos secundários) (THRANE, 1989). Esses métodos, exceto a identificação de micotoxinas geralmente consomem muito tempo, apresentam baixa especificidade e exigem pessoal com experiência (GAN et al., 1997).

Por meio dos métodos tradicionais de cultivo, fungos danificados ou inativados pelo calor dificilmente são detectados e a detecção de micélio por microscopia não é precisa, enquanto os métodos químicos são particularmente laboriosos (NOTERMANS et al., 1986). Os métodos microbiológicos podem demorar em torno de 6-7 dias e necessita de pessoal com experiência (BANKS; 
COX; NORTTHWAY, 1993). O gênero Fusarium apresenta variabilidade morfológica em cultura e pode sofrer mutações com repetidos repiques em meios de cultura normalmente utilizados em laboratório. Embora a identificação de metabólitos secundários específicos forneça informações confirmatórias úteis, seu uso é limitado, uma vez que as espécies fúngicas nem sempre produzem os mesmos metabólitos sob todas as condições (ABRAMSON et al., 1998). Processos de identificação inadequados do gênero Fusarium geram problemas taxonômicos, resultando em uma considerável divergência na extensa literatura da micotoxicologia deste gênero (GAN et al., 1997).

Durante as últimas décadas, novos métodos que permitem uma rápida identificação têm sido estudados, sendo alguns destes baseados em ensaios imunológicos (LI; MARQUARDT; ABRAMSON, 2000).

O uso de anticorpos em várias técnicas imunológicas tem se tornado uma importante ferramenta de diagnóstico para a identificação de fitopatógenos (COREL, 1992). A imunotaxonomia também tem sido aplicada rotineiramente em outras áreas como medicina, alimentos e biotecnologia (NOTERMANS et al., 1998).

A marcação enzimática de anticorpos foi adaptada para a detecção de fitopatógenos com grande sensibilidade, originando a metodologia de ELISA (Enzyme-Linked Immunosorbent Assay) (CLARK; ADAMS, 1977). Um dos reagentes é adsorvido na superfície de uma fase sólida, como uma placa de poliestireno com 96 cavidades. A reação é baseada na ligação reversível e não-covalente do antígeno com o anticorpo específico (CANDLISH, 1991). Uma enzima (freqüentemente peroxidase ou fosfatase alcalina) conjugada a um anticorpo reage com um substrato incolor para originar um produto colorido ou quimioluminescente, permitindo assim detectar o antígeno.

Dentre as principais vantagens na utilização dos ELISAs estão a alta sensibilidade (capacidade de detectar quantidades tão baixas quanto $\mathrm{ng} / \mathrm{mL}$ de fungos em alimentos) e especificidade, aliadas à facilidade na execução, permitindo a automatização do ensaio. Assim, um grande número de amostras pode ser analisado em tempo reduzido e custo relativamente baixo. Estes métodos são promissores devido a sua simplicidade, que permite uma análise rápida para o controle de qualidade tanto no campo como na indústria (PESTKA; ABOUZEID; SUTIKNO, 1995; LI; MARQUARDT; ABRAMSON, 2000; ONO et al., 2000).

O ELISA pode detectar a presença de fungos em alimentos mesmo após tratamento térmico, filtração ou irradiação gama, possibilitando avaliar a contaminação em alimentos processados. Enquanto os métodos convencionais detectam o número de propágulos viáveis, os imunoensaios podem revelar a quantidade de biomassa fúngica (NOTERMANS et al., 1986; DE RUITER et al., 1996).

Os ELISAs mais utilizados para a detecção de fungos toxigênicos em alimentos são o competitivo direto, o competitivo indireto e o ELISA sanduíche. No ELISA competitivo direto, a microplaca é sensibilizada com anticorpo (Figura 1). $\mathrm{O}$ antígeno marcado com a enzima é misturado com a amostra contendo o antígeno, que compete pelo anticorpo de quantidade limitada, portanto quanto maior a quantidade de antígeno na amostra, menor quantidade de antígeno marcado ligar-se-á ao anticorpo. Assim, a absorvância após a adição do substrato será inversamente proporcional à concentração do antígeno presente na amostra (HEFLE, 1995). 


\section{Anticorpo adsowido à microplaca}

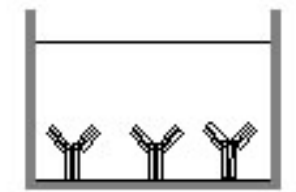

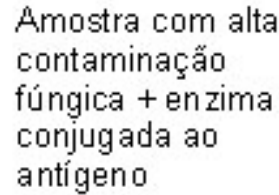
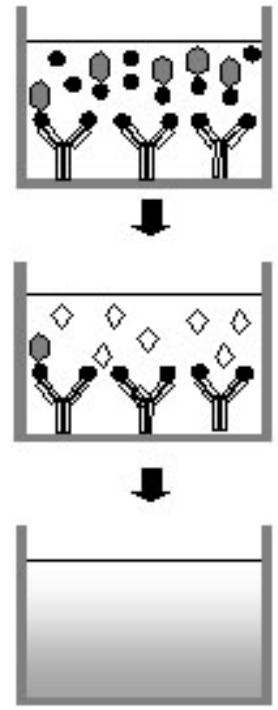

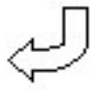<smiles>C1CCCCCCCCC1</smiles>

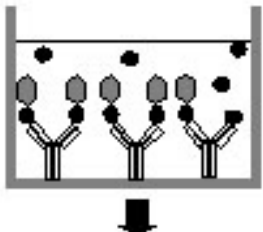

Amostra com baixa contaminaçã̃o fúngica + enzima conjugada a o antígeno
De senvolvimento de cor

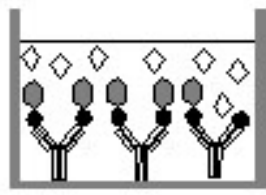

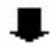

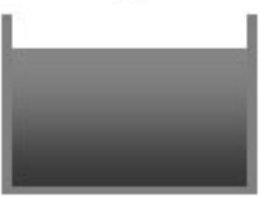

Figura 1. ELISA competitivo direto

Fonte: Adaptada de ONO et al. (2004)

No ELISA competitivo indireto, a sensibilização da microplaca é realizada com o antígeno (Figura 2). $\mathrm{Na}$ etapa seguinte, a amostra contendo o antígeno e o anticorpo são adicionados à microplaca. Quanto mais antígeno estiver presente na amostra, menos anticorpo livre estará disponível para o antígeno fixado à placa. A adição de um anticorpo secundário marcado com enzima, específico para o anticorpo primário, pode determinar a quantidade de anticorpo primário ligado à placa. Assim, quanto maior a concentração de antígeno na amostra, menor a absorvância (HEFLE, 1995).
O ELISA sanduíche apresenta duas etapas de complexação (Figura 3). Na primeira etapa os anticorpos não marcados são fixados na microplaca e reagem com o antígeno presente na amostra, promovendo sua captura e imobilização. Na segunda etapa, um segundo anticorpo marcado com a enzima e específico para um epítopo diferente no antígeno é adicionado para reagir com o antígeno ligado. Após a remoção de qualquer anticorpo secundário livre, o substrato é adicionado e com a ação da enzima ocorrerá uma mudança na cor. A intensidade da cor é diretamente proporcional à ligação do anticorpo marcado e, conseqüentemente à quantidade de antígeno presente na amostra (HEFLE, 1995). 


\section{Antígeno adsorvido à microplaca}

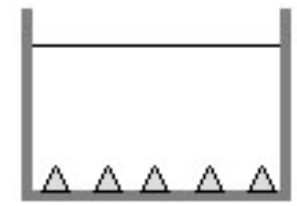

Amostra com alta contaminaçä̃o

fúngica + anticorpo

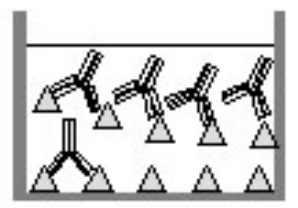

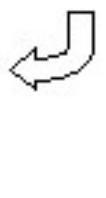<smiles>C1CCCCCCCC1</smiles>

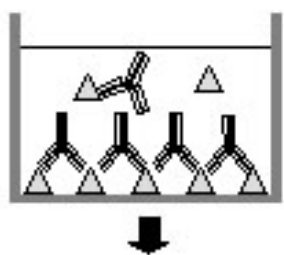

Amostra com baixa contaminaçẫo fúngica + anticorpo

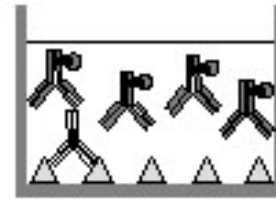

7

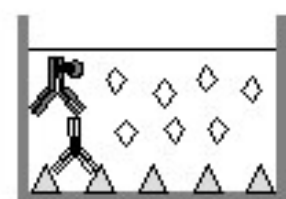

Adiçẫo de substrato/ cromógeno

Adiçẫo de enzima conjugada ao anticorpo

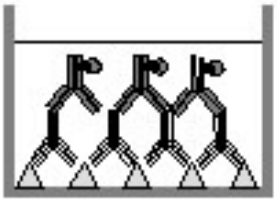

$+$

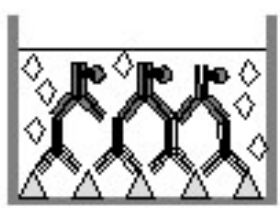

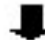

De senvolvimento de cor

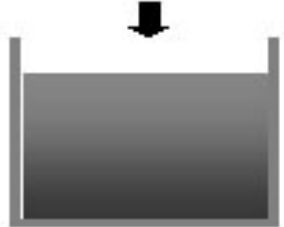

Figura 2. ELISA competitivo indireto Fonte: Adaptada de ONO et al. (2004)

A detecção de fungos em alimentos pode ser realizada, de maneira geral, para detecção de todos os fungos presentes, para detecção de um fungo específico ou um grupo de fungos relacionados (COUSIN, 1990).

No desenvolvimento de um ELISA para detecção de fungos em alimentos, os dois pontos principais consistem no limite de detecção do antígeno fúngico ou sensibilidade e na especificidade do anticorpo (LIN; COUSIN, 1987). Dessa forma, é necessário determinar a especificidade do ensaio para reduzir os resultados falso-positivos (TSAI; COUSIN, 1990). Além disso, a relação entre a quantidade do fungo e o valor da absorvância para o ELISA deve ser linear, para que a sensibilidade do ensaio possa ser determinada (COUSIN, 1990).

Pela sua simplicidade, rapidez, possibilidade de automatização e análise simultânea de um grande número de amostras, a técnica de ELISA trouxe precisão e praticidade ao diagnóstico de rotina de agentes fitopatogênicos e permitiu o desenvolvimento de inúmeros kits de diagnóstico (MARINHO, 2001).

Os ensaios imunoenzimáticos (ELISA) têm sido empregados para detectar antígenos de micélio, polissacarídeos extracelulares ou exoantígenos produzidos pelos fungos (Tabela 1), como será descrito a seguir. 

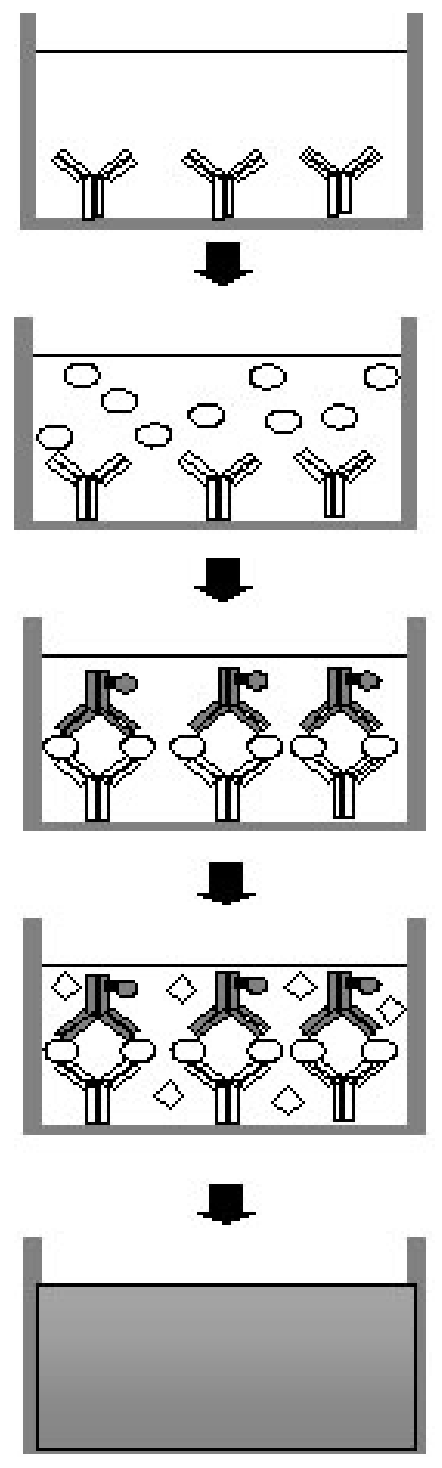

Figura 3. ELISA sanduíche

Fonte: Adaptada de ONO et al. (2006).
Anticorpo adsorvido à microplaca

Adiçẫo de amostra com antígeno fúngico

Adiçẫo de enzima conjugada ao anticorpo

Adiçẫo de substrato/cromógeno

Desenvolvimento de cor 
Tabela 1. Detecção de fungos em alimentos por ELISA

\begin{tabular}{|c|c|c|c|c|c|}
\hline Fungos & $\begin{array}{l}\text { Tipo de } \\
\text { ELISA } \\
\end{array}$ & $\begin{array}{c}\text { Tipo de } \\
\text { Anticorpo } \\
\end{array}$ & $\begin{array}{c}\text { Tipo de } \\
\text { Antígenos } \\
\end{array}$ & $\begin{array}{c}\text { Sensibilidade } \\
(\mu \mathrm{g} / \mathrm{mL})\end{array}$ & Referência \\
\hline Penicillium marneffei & Indireto & Policlonal & $\operatorname{ExAg}^{\mathrm{b}}$ & $-{ }^{\mathrm{d}}$ & Sekhon et al. (1982) \\
\hline $\begin{array}{l}\text { Mucor racemosus } \\
P . \text { verrucosum } \text { var } \\
\text { cyclopium } \\
\text { Fusarium oxysporum }\end{array}$ & ic-ELISA $^{\text {a }}$ & Policlonal & ExAg & - & $\begin{array}{c}\text { Notermans e } \\
\text { Heulvelman (1985) }\end{array}$ \\
\hline Penicillium spp. & Sanduíche & Policlonal & $\mathrm{EPS}^{\mathrm{c}}$ & $0,38 \mathrm{ng} / \mathrm{g}$ & $\begin{array}{l}\text { Notermans et al. } \\
\text { (1986) }\end{array}$ \\
\hline $\begin{array}{l}\text { Geotrichum candidum } \\
\text { Rhizopus stolonifer } \\
\text { Alternaria alternata }\end{array}$ & Sanduíche & Policlonal & Miceliais & 1,0 & $\begin{array}{c}\text { Lin et al. (1986) } \\
\text { Lin e Cousin } 1987\end{array}$ \\
\hline $\begin{array}{l}\text { Aspergillus versicolor } \\
\text { Cladosporium herbarum } \\
\text { G. candidum } \\
\text { M. circinelloides } \\
\text { P. chrysogenum }\end{array}$ & Sanduíche & Policlonal & ExAg & $0,01-1,0$ & Tsai e Cousin (1990) \\
\hline P. aurantiogriseum & Indireto & $\begin{array}{l}\text { Policlonal } \\
\text { Monoclonal }\end{array}$ & ExAg & - & Banks et al. (1993) \\
\hline P. aurantiogriseum & ic-ELISA & Policlonal & ExAg & 1,0 & Lu et al. (1994) \\
\hline A. ochraceus & ic-ELISA & Policlonal & ExAg & 0,19 & Lu et al. (1995) \\
\hline A. parasiticus & Indireto & Policlonal & ExAg & - & Shapira et al. (1997) \\
\hline $\begin{array}{l}\text { F. graminearum } \\
\text { F. sporotrichioides } \\
\text { F. poae }\end{array}$ & ic-ELISA & Policlonal & $\begin{array}{c}\text { ExAg } \\
\text { Miceliais }\end{array}$ & - & Gan et al. (1997) \\
\hline Fusarium spp. & ic-ELISA & Policlonal & ExAg & - & $\begin{array}{c}\text { Abramson et al. } \\
\text { (1998) }\end{array}$ \\
\hline $\begin{array}{l}\text { A. ochraceus } \\
\text { A. flavus } \\
\text { A. versicolor }\end{array}$ & ic-ELISA & Policlonal & ExAg & $0,42-1,21$ & Chen et al. (2000) \\
\hline A. parasiticus & Sanduíche & Policlonal & ExAg & - & Yong e Cousin (2001) \\
\hline Fusarium spp. & Sanduíche & Monoclonal & EPS & 0,001 & Kwak et al. (2003) \\
\hline $\begin{array}{l}F \text {. verticllioides } \\
F . \text { graminearum }\end{array}$ & Indireto & Policlonal & Miceliais & $0,1-1,0$ & Iyer e Cousin (2003) \\
\hline F. verticillioides & ic-ELISA & Policlonal & ExAg & 0,26 & Meirelles (2005) \\
\hline
\end{tabular}

${ }^{a}$ ELISA competitivo indireto

${ }^{b}$ Exoantígenos

'Exopolissacarídeos

¿Sensibilidade não avaliada ou não citada na referência. 


\section{ELISA na Detecção de Fungos em Alimentos}

Em um dos primeiros estudos utilizando os ensaios imunoenzimáticos para a identificação de fungos, Sekhon, Li e Garg (1982) observaram que anticorpos policlonais para exoantígenos de Penicillium marneffei reagiam apenas com cepas desta espécie e com uma espécie de Penicillium não identificada, não havendo reação cruzada com exoantígenos de outras espécies deste gênero ou do gênero Aspergillus.

Notermans e Heuvelman (1985) desenvolveram um ELISA para detectar fungos em alimentos processados e não processados, utilizando antígenos de Penicillium verrucosum var. cyclopium, Mucor racemosus e Fusarium oxysporum. Houve forte reação cruzada entre as frações antigênicas de $M$. racemosus com todas as espécies de Mucor e Rhizopus, indicando a presença de antígenos ou epítopos em comum entre os dois gêneros, provavelmente por serem grupos taxonomicamente próximos. As frações antigênicas de $F$. oxysporum apresentaram reação cruzada evidente com outras espécies do mesmo gênero e pouca reação com outros gêneros. As frações antigênicas de $P$. verrucosum apresentaram reação cruzada com todas as espécies do mesmo gênero, e espécies de Aspergillus testadas. Neste trabalho pôde-se concluir que os antígenos eram termoestáveis, gênero específicos e detectáveis apenas em alimentos contaminados.

O potencial do ELISA para detecção de fungos em uma ampla variedade de alimentos foi avaliado utilizando antígenos polissacarídicos extracelulares de Penicillium spp. e Aspergillus spp. (NOTERMANS et al., 1986). Foram analisadas 188 amostras de diferentes produtos alimentícios naturalmente e artificialmente contaminadas com fungos produtores de micotoxinas. Os antígenos de ambos os fungos estavam presentes em todas as amostras contendo aflatoxina $\mathrm{B}_{1}$, e a concentração de antígenos estava relacionada com a concentração desta toxina. Assim, foi observado que o antígeno é produzido sob todas as condições que permitem a produção de aflatoxinas. Os autores concluíram que o ELISA para detecção de fungos em alimentos é um método sensível e confiável para detectar fungos em alimentos nos estágios iniciais da contaminação. Por outro lado, a maioria dos ensaios baseados em polissacarídeos extracelulares tem demonstrado, até o momento, baixa especificidade, o que pode estar relacionado com a natureza do antígeno. Assim, estes antígenos não podem ser usados para distinguir espécies ou gêneros relacionados como Aspergillus e Penicillium (LI; MARQUARDT; ABRAMSON, 2000).

Lin, Lister e Cousin (1986) desenvolveram um ELISA sanduíche para a detecção de Alternaria alternata, Geotrichum candidum e Rhizopus stolonifer em purê de tomate e compararam a eficiência deste método na detecção de fungos crescidos em meio de cultivo artificial, tomate fresco e processado. Anticorpos foram obtidos por meio da imunização de coelhos com homogenatos de fungos liofilizados, sendo que o principal componente antigênico constituiu-se de polissacarídeos. Não houve alteração da eficiência do método em cada situação, reforçando que o ensaio imunoenzimático é viável para a análise de alimentos processados. A porcentagem de reação cruzada entre as três espécies foi menor que $10 \%$ e a sensibilidade deste imunoensaio foi maior do que a maioria dos métodos químicos, sendo o limite de detecção de aproximadamente $1 \mu \mathrm{g} / \mathrm{g}$ de amostra. Foi observada uma correlação positiva entre as absorvâncias do ELISA e a quantidade de fungos ( $\mu \mathrm{g}$ de fungos/g de amostra) no purê.

Lin e Cousin (1987) isolaram e caracterizaram os antígenos do extrato fúngico das três espécies supracitadas e avaliaram o uso deste imunoensaio para a detecção de fungos em diferentes alimentos como frutas e vegetais processados, pão e queijo. A especificidade do anticorpo contra A. alternata, $G$. candidum e $R$. stolonifer foi avaliada usando 21 espécies de fungos e 7 espécies de leveduras. Não 
foi observada reação cruzada dos anticorpos com antígenos de leveduras. O ELISA foi capaz de detectar tanto as espécies viáveis como as não viáveis (aquecidas e liofilizadas), sendo considerado relativamente específico, embora a ocorrência de reação cruzada tenha sido observada entre alguns fungos.

Anticorpos policlonais produzidos contra exoantígenos de Aspergillus versicolor, Cladosporium herbarum, Geotrichum candidum, Mucor circinelloides e Penicilium chrysogenum para o desenvolvimento de um ELISA para detecção de fungos em produtos lácteos (TSAI; COUSIN, 1990) apresentou uma sensibilidade variando entre $1 \mathrm{ng}$ a $1 \mu \mathrm{g} / \mathrm{mL}$ dependendo do fungo testado. Anticorpos contra Cladosporium, Geotrichum e Mucor apresentaram reatividade cruzada apenas com espécies do mesmo gênero, enquanto que os anticorpos contra Aspergillus e Penicillium apresentaram reatividade cruzada entre si. Isto pode ter ocorrido pelo fato destes dois gêneros pertencerem à mesma família e apresentarem composição química celular semelhante (COUSIN et al., 1990). Os fungos foram detectados nos alimentos no segundo dia de contaminação, antes que esta se tornasse visível.

Banks, Cox e Northway (1993) produziram anticorpos policlonais e monoclonais contra antígenos micelianos solúveis de $P$. aurantiogriseum e avaliaram a ocorrência de reação cruzada com 10 fungos de campo e 27 fungos de armazenamento. Os anticorpos policlonais e monoclonais apresentaram reação cruzada com 33 e 37 fungos, respectivamente. Os anticorpos obtidos poderiam ser empregados em imunoensaios de amplo espectro para detecção de fungos.

Um ELISA indireto desenvolvido para identificação de Penicillium aurantiogriseum demonstrou que os anticorpos policlonais produzidos eram específicos para exoantígenos desta espécie. $\mathrm{O}$ ensaio apresentou boa sensibilidade para exoantígenos de $P$. aurantiogriseum $(1,0 \mu \mathrm{g} / \mathrm{mL}$ de soro), com baixa ou nenhuma reação cruzada com extratos solúveis de quatro tipos de grãos (trigo, cevada, milho e soja) e com antígenos de outras cinco espécies de Penicillium ( $P$. chrysogenum, $P$. citrinum, $P$. commune, $P$. roqueforti e $P$. verrucosum), quatro espécies de Aspergillus ( $A$. candidus, A. flavus, A ochraceus e A. versicolor), três espécies de Fusarium ( $F$. avenaceum, $F$. equiseti e F. poae), duas de Mucor e Alternaria alternata (LU et al., 1994).

Lu, Marquardt e Kierek-Jaszczuk (1995) desenvolveram um ELISA competitivo indireto baseado em anticorpos policlonais produzidos contra exoantígenos de Aspergillus ochraceus. Dentre 16 espécies fúngicas pertencentes a 5 gêneros, os anticorpos reconheceram apenas os exoantígenos de A. ochraceus e, em menor grau ( $\mathrm{d} \leq 2,5 \%)$, outras três espécies de Aspergillus (A. candidus, A. flavus e $A$. versicolor). A sensibilidade apresentada pelos anticorpos foi de $190 \mathrm{ng} / \mathrm{ml}$. Os resultados demonstraram que o ELISA competitivo desenvolvido utilizando anticorpos policlonais contra os exoantígenos de $A$. ochraceus foi quantitativo e espécie-específico, sugerindo que estes anticorpos podem ser utilizados na detecção deste fungo em grãos que também estejam contaminados com outras espécies fúngicas.

Chen et al. (2000) desenvolveram um ELISA competitivo indireto baseado em anticorpos policlonais produzidos em galinhas empregando exoantígenos de 3 espécies de Aspergillus (A. flavus, A. ochraceus e A. versicolor). A ocorrência de reação cruzada foi avaliada com diferentes espécies de Aspergillus (A. parasiticus, A. niger, A. fumigatus, A. oryzae, A. sydiwii e $A$. terreus), isolados de diferentes gêneros de fungos (Penicillium spp., Rhyzopus spp., Mucor spp. e Trichoderma spp.) e com extrato de grãos (mistura de milho, trigo, arroz, cevada, amendoim, soja, sorgo e semente de algodão). Os anticorpos para o exoantígeno de $A$. ochraceus foram espécie-específicos, enquanto os anticorpos contra $A$. flavus e A. versicolor apresentaram 
reação cruzada com outras espécies de Aspergillus em vários graus. Os anticorpos produzidos não apresentaram reação cruzada com os exoantígenos de outros gêneros de fungos e com o extrato de grãos. Os anticorpos produzidos contra exoantígenos de $A$. ochraceus apresentaram uma sensibilidade de $0,61 \mu \mathrm{g} /$ $\mathrm{mL}$. Estes resultados reforçam aqueles obtidos por $\mathrm{Lu}$, Marquardt e Kierek-Jaszczuk (1995), mostrando que o ensaio imunoenzimático para exoantígenos pode ser empregado para identificar e detectar o gênero Aspergillus em grãos (CHEN et al., 2000).

Os anticorpos produzidos contra exoantígenos de um isolado aflatoxigênico de $A$. parasiticus apresentaram reação cruzada com espécies dos gêneros Aspergillus e Penicillium (SHAPIRA et al., 1997). Por outro lado, os anticorpos produzidos contra as proteínas quiméricas envolvidas com a biossíntese de aflatoxinas foram altamente específicos. Assim, a produção de anticorpos contra enzimas-chave da via biossintética da micotoxina representa uma alternativa interessante para a redução de reações inespecíficas.

O ELISA competitivo indireto baseado em anticorpos policlonais contra exoantígenos de $A$. parasiticus apresentou reação cruzada apenas para espécies com fenótipos similares como $A$. flavus, $A$. oryzae e $A$. sojae (YONG; COUSIN, 2001). Foi realizada uma comparação entre a detecção do fungo por ELISA e a de aflatoxinas nos grãos em duas temperaturas diferentes de cultivo $\left(15^{\circ} \mathrm{C}\right.$ e $\left.21^{\circ} \mathrm{C}\right)$. Os resultados indicaram que em milho, no cultivo a $15^{\circ} \mathrm{C}$ os antígenos puderam ser detectados no $4^{\circ}$ dia, quando a concentração de aflatoxinas era de 0,16 $\mathrm{ng} / \mathrm{g}$; enquanto que a $21^{\circ} \mathrm{C}$, os exoantígenos foram detectados também no $4^{\circ}$ dia, porém neste período aflatoxinas não foram detectadas. Por outro lado, em amendoim, os exoantígenos foram detectados no $4^{\circ}$ dia a $15^{\circ} \mathrm{C}$ e no $2^{\circ}$ dia a $21^{\circ} \mathrm{C}$. Em ambas as condições não foram detectadas aflatoxinas nos períodos avaliados. Estes resultados demonstram que os exoantígenos podem ser detectados antes mesmo da produção de micotoxinas, permitindo melhor controle de qualidade dos alimentos.
Gan et al. (1997) desenvolveram um ensaio imunoenzimático capaz de identificar espécies toxigênicas de Fusarium, além de determinar a concentração de exoantígenos em grãos. Galinhas foram imunizadas com antígenos micelianos solúveis e exoantígenos de F. sporotrichioides, $F$. poae e $F$. graminearum, seguida de caracterização dos antígenos por ELISA. Os anticorpos produzidos contra os antígenos micelianos solúveis apresentaram reatividade cruzada com os antígenos de outros gêneros, inviabilizando a sua utilização no imunodiagnóstico. Por outro lado, os anticorpos contra os exoantígenos de $F$. poae eram espécieespecíficos. Os resultados indicaram que os exoantígenos eram mais adequados para a produção de anticorpos específicos do que os antígenos micelianos solúveis e, que ensaios imunoenzimáticos com exoantígenos podem ser empregados para o imunodiagnóstico e imunoidentificação de Fusarium spp.

O imunoensaio desenvolvido por Gan et al. (1997) também foi empregado para estimar as concentrações de exoantígenos de Fusarium em amostras de trigo macio e duro (ABRAMSON et al., 1998). Estas amostras também foram avaliadas quanto à presença da micotoxina deoxinivalenol e ergosterol, um metabólito que reflete a biomassa fúngica. Empregando o anticorpo produzido contra F. sporotrichioides, a correlação entre os níveis de exoantígenos e as concentrações de deoxinivalenol apresentou coeficientes de 0,80 e 0,76 para as amostras de trigo duro e macio, respectivamente. Com o mesmo anticorpo, as correlações lineares entre os níveis de exoantígenos e a concentração de ergosterol total para as amostras de trigo duro e macio apresentaram coeficientes de 0,66 e 0,81, respectivamente, indicando que a quantidade de exoantígenos produzida por $F$. graminearum está diretamente relacionada à biomassa. Este estudo demonstrou que os imunoensaios que empregam exoantígenos podem ser úteis para a detecção e quantificação da contaminação por Fusarium em amostras de trigo duro e macio. $\mathrm{O}$ anticorpo gênero- 
específico permite a detecção de Fusarium na presença de outros fungos de maneira rápida e simples (GAN et al., 1997). Este teste também pode ser útil para avaliação pré-colheita de espécies de Fusarium em amostras de trigo, podendo ser um sinal de advertência quanto à possível produção de deoxinivalenol em cereais e seus derivados (ABRAMSON et al., 1998).

Um ELISA sanduíche baseado em anticorpos monoclonais específicos para polissacarídeos extracelulares de Fusarium verticillioides apresentou um limite de detecção de $1 \mathrm{ng} / \mathrm{mL}$. Entre as 59 linhagens testadas, a maioria das espécies de Fusarium apresentou reatividade alta, enquanto que nos outros gêneros não foi observada reação cruzada, exceto A. versicolor e Trichoderma viride. $\mathrm{O}$ coeficiente de correlação entre os níveis de polissacarídeos extracelulares (ELISA sanduíche) e o peso seco do micélio (cultura líquida de $F$. verticillioides) foi 0,97 , enquanto que a correlação entre os polissacarídeos extracelulares e as unidades formadoras de colônias em cultura sólida foi de 0,91 (KWAK et al., 2003).

Iyer e Cousin (2003) desenvolveram um ELISA indireto para detectar espécies de Fusarium em fubá, utilizando antígenos micelianos de $F$. verticillioides e $F$. graminearum. A especificidade dos anticorpos policlonais foi avaliada contra 70 espécies de fungos e leveduras pertencentes a 23 gêneros. Os resultados mostraram que não houve reatividade cruzada para a maioria dos fungos e para nenhuma das leveduras analisadas. Entre os fungos testados, apenas Eurotium repens, espécies de Monascus, Phoma exígua, Verticillium albo-atrum e a maioria das espécies de Fusarium apresentaram reatividade superior a $30 \%$. As quatro espécies não pertencentes a Fusarium podem apresentar epítopos em comum com as espécies utilizadas para a produção de anticorpos. Os fungos puderam ser detectados por ELISA num período de 24 a 36h após a inoculação no fubá $\left(10^{2}\right.$ a $\left.10^{3} \mathrm{UFC} / \mathrm{mL}\right)$ embora ainda não pudessem ser visualizados pelo método de contagem em placa. Os dados obtidos indicaram que o ELISA indireto desenvolvido neste estudo pode detectar espécies de Fusarium mais rapidamente do que o método tradicional de contagem em placa.

Meirelles (2005) desenvolveu um ELISA competitivo indireto baseado em anticorpos policlonais para detectar Fusarium spp. em milho, utilizando exoantígenos de $F$. verticillioides e avaliou a correlação entre esta metodologia com os métodos tradicionais de detecção de fungos (ergosterol e biomassa fúngica). $\mathrm{O}$ coeficiente de correlação entre a concentração de exoantígenos e ergosterol foi 0,52 em amostras de milho recém-colhido, enquanto que entre exoantígenos e biomassa em caldo BHI (infusão de cérebro e coração) foi 0,84 . Os resultados sugeriram que este ELISA apresenta potencial para a detecção de Fusarium spp. em amostras de milho.

Esses ensaios mostraram-se muito úteis não só na detecção de fungos, mas também na quantificação dos mesmos em alimentos, pelo fato de a produção de exoantígenos estar relacionada à biomassa fúngica (NOTERMANS; HEUVELMAN, 1985; NOTERMANS; SOENTORO, 1986; BANKS; COX; NORTHWAY, 1993; DEWEY et al., 1993).

Além de serem utilizados na identificação de fungos, os exoantígenos têm sido empregados para diferenciar vários fungos morfologicamente similares. Notermans e Soentoro (1986) demonstraram que anticorpos produzidos contra polissacarídeos extracelulares de Penicillium digitatum eram reativos com sobrenadantes de cultivo do gênero Aspergillus e de outras espécies do gênero Penicillium, exceto com espécies do subgênero Biverticillium.

Kaufmann e Standard (1987) sugeriram que as características antigênicas dos fungos poderiam ser utilizadas na taxonomia de fungos, uma vez que são produzidas durante todo o crescimento do fungo e geralmente são independentes do meio de cultura, temperatura ou idade do cultivo.

Fuhrmann et al. (1989) demonstraram que anticorpos produzidos contra antígenos de Penicillium verrucosum var. verrucosum reconheciam apenas 
antígenos de espécies de Penicillium, exceto aquelas pertencentes ao subgênero Aspergilloides.

Anticorpos produzidos contra exoantígenos de Cladosporium cladosporioides e C. herbarum mostraram-se específicos para o gênero Cladosporium, enquanto que anticorpos contra Mucor racemosus e M. circinelloides eram reativos com antígenos dos gêneros Mucor, Rhizomucor, Rhizopus, Thamnidium, Absidia e Syncephalastrum, todos pertencentes à ordem Mucorales (NOTERMANS; SOENTORO, 1986; TSAI; COUSIN, 1990; DE RUITER et al., 1991).

Esses resultados mostram que as características antigênicas podem ser utilizadas como ferramenta na taxonomia até o nível de gênero, porém, com o aprimoramento da técnica pode ser possível atingir o nível de espécie.

\section{Considerações Finais}

Os métodos de detecção e quantificação de fungos em produtos destinados ao consumo humano e animal são essenciais para o controle de qualidade de alimentos. Os ensaios imunoenzimáticos apresentam potencial para a detecção de microrganismos, podendo identificar tanto gêneros quanto espécies fúngicas. Muitos estudos realizados até o momento demonstraram que os imunoensaios para exoantígenos podem ser úteis na detecção de diversos fungos toxigênicos.

Desta forma, os ensaios imunoenzimáticos terão papel cada vez mais importante na análise de alimentos, disponibilizando ferramentas que poderão ser utilizadas tanto nos laboratórios como ensaios quantitativos, como no campo, para a triagem.

\section{Agradecimentos}

Os autores agradecem ao CNPq, FINEP, à CAPES, à Fundação Araucária, ao Fundo Paraná/ SETI e à Universidade Estadual de Londrina, pelo apoio financeiro.

\section{Referências}

ABBAS, A. K.; LICHTMAN, A. H.; POBER, J. S. Imunologia celular e molecular. 3.ed. Rio de Janeiro: RevinteR, 2000.

ABRAMSON, D.; GAN, Z.; CLEAR, R. M.; GILBERT, J.; MARQUARDT, R. R. Relationships among deoxynivalenol, ergosterol and Fusarium exoantigens in Canadian hard and soft wheat. International Journal of Food Microbiology, Amsterdam, v.45, n.3, p.217-224, 1998.

AYRES, J. C. Significance of food mycology - an overview. In: RHODES, M. E. Food Mycology. Massachusetts: G. K. Hall \& Co., 1979. p.3-10.

BANKS, J. N.; COX, S. J.; NORTHWAY, B. J. Polyclonal and monoclonal antibodies to field and storage fungi. International Biodeterioration \& Biodegradation, Barking, v.32, n.1-3, p.137-144, 1993.

BENNET, G. A.; RICHARD, J. L. Liquid chromatographic method for analysis of the naphthalene dicarboxialdehyde derivative of fumonisins. Journal of the Association of Official Analytical Chemistry International, Arlington, v.77, n.2, p.501-506, 1994.

CANDLISH, A. A. G. Immunological methods in food microbiology. Food Microbiology, London, v.8, p.1-14, 1991.

CHEN, F. S.; CHEN, J. W.; ZHAO, S.; GAN, Z.; LUO, X. C.; ZHOU, Q. Characterization of chicken antisera raised against Aspergillus spp. by enzyme-linked immunosorbent assay. Nahrung, Berlin, v.44, n.5, p.323327,2000 .

CLARK, M. F.; ADAMS, A. N. Characteristics of the microplate method of enzyme-linked immunosorbent assay for the detection of plant viruses. The Journal of General Virology, London, v.34, p.475, mar. 1977.

COREL, J. C. Genetic, biochemical and molecular techniques for the identification and detection of soil borne plant pathogenic fungi. In: SINGLETON, L. L.; MIHAIL, J. D.; RUSH, C. M. (Ed.) Methods for Research on Soil borne Phytopathogenic Fungi, St Paul, MN: APS Press, 1992. p.7-16.

COUSIN, M. A.; DUFRENNE, J.; ROMBOUTS, F. M.; NOTERMANS, S. Immunological detection of Botrytis and Monascus species in food. Food Microbiology, Amsterdam, v.7, p.227-235, 1990.

DE RUITER, G. A.; NOTERMANS, S. H. W.; DE NIJS, M.; ROMBOUTS, F. M. Immunochemical detection of moulds in food. Cerevisia, Bruxelles, v.21, n.4, p.59-61, 1996.

DE RUITER, G. A.; VAN DER LUGT, A. W.; VORAGEN, A. G. J.; ROMBOUTS, F. M.; NOTERMANS, S. H. W. Highperformance size-exclusion chromatography and ELISA 
detection of extracellular polysaccharides from Mucorales. Carbohydrate Research, Amsterdam, v.21, p.47-57, 1991.

DEWEY, F. M.; BANHAM, A. H.; PRIESTLEY, R. A.; MARTIN, B.; HAWES, C.; PHILLIPS, S. I.; WAREING, P. W. Monoclonal antibodies for the detection of spoilage fungi. International Biodegradation \& Biodeterioration, Barking, v.32, n.1-3, p.127-136, 1993.

FUHRMANN, B.; ROQUEBERT, M. F.; van HOEGAERDEN, M.; STROSSBERG, A. D. Immunological differentiation of Penicillium species. Canadian Journal of Microbiology, Ottawa, v.35, n.11, p.1043-1047, nov. 1989.

GAN, Z.; MARQUARDT, R. R.; ABRAMSON, D.; CLEAR, R. M. The characterization of chicken antibodies raised against Fusarium spp. by enzyme-linked immunosorbent assay and immunobloting. International Journal of Food Microbiology, Amsterdam, v.38, n.2-3, p.191-200, sep. 1997.

GOURAMA, H.; BULLERMAN, L. B. Detection of molds in food and feeds: potential rapid and selective methods. Journal of Food Protection, Des Moines, v.58, n.12, p.1389-1394, 1995.

HEFLE, S. L. Immunoassay fundamentals. Food Technology, Chicago, v.49, n.2, p.102-107, 1995.

IYER, M. S.; COUSIN, M. A. Immunological detection of Fusarium species in cornmeal. Journal of Food Protection, Des Moines, v.66, n.3, p.451-456, 2003.

JARVIS, B.; SCILER, D. A. L.; OULD, A. J. L.; WILLIAMS, A. P. Observations on the enumeration of molds in food and feedstuffs. Journal of Applied Bacteriology, Oxford, v.55, n.2, p.325-336, 1983.

KAUFMANN, L.; STANDARD, P. G. Specific and rapid identification of medically important fungi by exoantigen detection. Annual Review of Microbiology, Palo Alto, v.41, p.209-225, 1987.

KERÉNYI, Z.; ZELLER, K.; HORNOK, L.; LESLIE, J. F. Molecular standardization of mating type terminology in the Gibberella fujikuroi species complex. Applied and Environmental Microbiology, Washington, v.65, n.9, p.4071-4076, 1999.

KWAK, B. Y.; KWON, B. J.; KWEON, C. H.; SHON, D. H. Detection of Fusarium species by enzyme-linked immunosorbent assay using monoclonal antibody. Journal of Microbiology and Biotechnology, v.13, n.5, p.794-799, 2003.

LI, S.; MARQUARDT, R. R.; ABRAMSON, D. Immunochemical detection of molds: a review. Journal of Food Protection, Des Moines, v.63, n.2, p.281-291, 2000.

LIN, H. H.; COUSIN, M. A. Evaluation of enzyme-linked immunosorbent assay for detection of molds in foods.
Journal of Food Science, Chicago, v.52, n.4, p.1089-1094, jul./ago. 1987.

LIN, H. H.; LISTER, R. M.; COUSIN, M. A. Enzyme-linked immunosorbent assay for detection of mold in tomato puree. Journal of Food Science, Chicago, v.51, n.1, p.180183, 1986.

LU, P.; MARQUARDT, R. R.; FROHLICH, A. A.; MILLS, J. T. Detection of Penicillium aurantiogriseum by ELISA utilizing antibodies produced against its exoantigens. Microbiology, New York, v.140, p.3267-3276, 1994.

LU, P.; MARQUARDT, R. R; KIEREK-JASZCZUK, D. Immunochemical detection of fungi using polyclonal antibodies raised in rabbits to exoantigens from Aspergillus ochraceus. Letters in Applied Microbiology, Oxford, v.20, p.41-45, 1995.

MARINHO, V. L. A. Técnicas imunológicas e moleculares no diagnóstico de vírus de plantas. In: FERNANDES, J. M.; PRESTES, A. M.; PICININI, E. C. (Ed.) Revisão Anual de Patologia de Plantas. Passo Fundo, RS: RAPP, 2001. v.9, p.383-402.

MEIRELLES, P. G. Fusarium verticillioides: Caracterização molecular e detecção em milho através de ensaio imunoenzimático. 2005. Dissertação (Mestrado em Biotecnologia) - Universidade Estadual de Londrina, Londrina.

NOTERMANS, S. H. W.; COUSIN, M. A.; DE RUITER, G. A.; ROMBOUTS, F. M. Fungal immunotaxonomy. In: FRISVAD, J. C.; BRIDGE, P. D.; ARORA, D. K. (Ed.). Chemical Fungal Taxonomy. New York: Marcel Dekker Inc., 1998. p.121-149.

NOTERMANS, S.; HEUVELMAN, C. J. Immunological detection of moulds in food by using the enzyme-linked immunosorbent assay (ELISA); preparation of antigens. International Journal of Food Microbiology, Amsterdam, v.2,p.247-258, 1985.

NOTERMANS, S.; HEUVELMAN, C. J.; VANEGMOND, H. P.; PAULSCH, W. E.; BESLING, J. R. Detection of mold in food by enzyme-linked immunosorbent assay. Journal of Food Protection, Des Moines, v.49, n.10, p.786-791, 1986.

NOTERMANS, S.; SOENTORO, P. S. S. Immunological relationship of extracellular polysaccharide antigens produced by different molds species. Antoine van Leeuwenhoek, Amsterdam, v.52, n.5, p.593-601, 1986.

ONO, E. Y. S.; BIAZON, L.; FUJII, S.; ONO, M. A.; HIROOKA, E. Y. Advances in immunochemical methods for mycotoxin/mycotoxigenic fungi detection in the agrifood system. In: GANGULI, B. N.; DESHMUKH, S. K. (Ed.) Fungi: Multifaceted Microbes. New Delhi: Anamaya Publishers, 2006. p.275-293. 
ONO, E. Y. S.; KAWAMURA, O.; ONO, M. A.; UENO, Y.; HIROOKA, E. Y. A comparative study of indirect competitive ELISA and HPLC for fumonisin detection in corn of the State of Paraná, Brazil. Food and Agricultural Immunology, Abingdon, v.12, n.1, p.5-14, 2000.

ONO, E. Y. S.; MENDES, A. M.; MEIRELLES, P. G.; HIROOKA, E. Y.; ONO, M. A. Micotoxinas em alimentos: Progressos na imunodectecção. Biotecnologia Ciência e Desenvolvimento, Brasilia, v.32, p.69-80, 2004.

PESTKA, J. J.; ABOUZEID, M. N.; SUTIKNO. Immunological assays for mycotoxins detection. Food Technology, Chicago, v.49, n.2, p.120-128, 1995.

ROITT, I.; BROSTOFF, J.; MALE, D. Imunologia. 6.ed. São Paulo: Manole, 2003.

SEKHON, A. S.; LI, J. S. K.; GARG, A. K. Penniciliosis marneffei: serological and exoantigen studies. Mycopathologia, Den Haag, v.77, p.51-57, 1982.

SHAPIRA, R.; PASTER, N.; MENASHEROV, M.; EYAL, O.; METT, A.; MEIRON, T.; KUTTIN, E.; SALOMON, R. Development of polyclonal antibodies for the detection of aflatoxigenic molds involving culture filtrate and chimeric proteins expressed in Escherichia coli. Applied and Environmental Microbiology, Washington, v.63, n.3, p.990-995, 1997.
STEENKAMP, E. T.; WINGFIELD, B. D.; COUTINHO, T. A.; ZELLER, K. A.; WINGFIELD, M. J.; MARASAS, W. F. O.; LESLIE, J. F. PCR-based identification of MAT-1 and MAT-2 in the Gibberella fujikuroi species complex. Applied and Environmental Microbiology, Washington, v.66, n.10, p.4378-4382, 2000.

THORNTON, C. R.; PITT, D.; WAKLEY, G. E.; TALBOT, N. J. Production of a monoclonal antibody specific to the genus Trichoderma and closely related fungi, and its use to detect Trichoderma spp. in naturally infested compost. Microbiology, Reading, v.148, p.1263-1279, 2002.

THRANE, U. Fusarium species and their specific profile of secondary metabolites. In: CHELKOWSKI, J. (Ed.) Fusarium: Mycotoxin, Taxonomy and Pathogenicity. Amsterdam: Elsevier Science, 1989. p.199-225

TSAI, G. J.; COUSIN, M. A. Enzyme-linked immunosorbent assay for detection of molds in cheese and yogurt. Journal of Dairy Science, Champaign, v.73, p.3366-3378, 1990.

YAU, K. Y. F.; LEE, H.; HALL, J. C. Emerging trends in the synthesis and improvement of hapten-specific recombinant antibodies. Biotechnology Advances, New York, v.21, n.7, p.599-637, 2003.

YONG, R. K.; COUSIN, M. A. Detection of moulds producing aflatoxins in maize and peanuts by an immunoassay. International Journal of Food Microbiology, Amsterdam, v.65, n.1-2, p.27-38, 2001. 